

\section{A ubiquidade das câmeras e a irrupção do real ${ }^{1,2}$}

\section{The ubiquity of cameras and the eruption of the real into images}

\author{
Felipe da Silva Polydoro ${ }^{3}$
}

\section{Resumo}

A disseminação de câmeras em dispositivos eletrônicos móveis e equipamentos de vigilância multiplica os registros visuais do mundo. Entre eles, estão os vídeos que captam a irrupção inesperada de um acontecimento alheio ao sujeito que filma, uma intromissão do real na cena que desorganiza os elementos e modifica até mesmo o estatuto da imagem. Neste texto, objetivamos conceituar tal tipo de imagem e, além disso, levantar referências teóricas para analisá-la, sobretudo com base no pensamento de Jacques Lacan. Além disso, analisamos alguns vídeos de acontecimentos de relevância midiática: o assassinato de Kennedy, o ataque terrorista de 11 de setembro, a queda de um meteorito na Rússia.

\section{Palavras-chave}

Imagem; acontecimento; análise da imagem.

\section{Abstract}

The availability of digital cameras in mobile electronic devices and surveillance equipment has caused an exponential increase in the number of visual recording of the world. Among them are videos that capture the unexpected eruption of events. The eruption of such events is a invasion of the real into the scene, disorganizing its elements and modifying the image status. The objective of this paper is to conceptualize this type of image in addition to refer to theoretical references in order to analyze them, mostly based on the theories of Jacques Lacan. Also, we analyze some videos that capture relevant events: Kennedy's assassination, the 9/11 terrorist attack and the fall of a meteorite in Russia.

\section{Keywords}

Image; event; image analysis. 
Para começar, um marco nos flagrantes imprevistos de acontecimentos: o registro amador do assassinato de John Kennedy, em novembro de 1963. O filme inicia e há dezesseis segundos de uma celebração política banal ${ }^{4}$. Dezesseis segundos que já de antemão qualquer espectador contemporâneo do Youtube tomará como espera, depois dos quais ouve-se um estampido e surge um borrão vermelho no rosto de Kennedy. A câmara acompanha o tráfego do carro por mais oito segundos, nos quais o rosto avermelhado segue inerte e Jacqueline Kennedy ao mesmo tempo grita e move-se para fora do carro.

Tal objeto audiovisual dota-se, portanto, da seguinte estrutura: dezesseis segundos de desfile; o tiro (que dura menos de um segundo); oito segundos que enquadram o carro em movimento, imediatamente após o tiro. Este filme amador, operado pelo imigrante ucraniano Abraham Zapruder, tornou-se um documento visual histórico porque o evento que se desenrolava reto e previsível diante da câmera foi interrompido no instante dezesseis. Algo externo ao enquadramento irrompe e modifica a relevância e, quiçá, o estatuto da imagem em questão - e o termo impreciso algo aplica-se aqui com perfeição, pois, no imaginário dos habitantes dos Estados Unidos, o assassinato de Kennedy jamais foi elucidado. Trinta e oito anos depois, em 11 de setembro de 2001, uma equipe de documentaristas que filmava a rotina de bombeiros nova-iorquinos captou o instante em que o primeiro avião se chocou contra o World Trade Center. Há dezenas, talvez centenas de vídeos da explosão da segunda aeronave - e ainda mais imagens da queda das torres. Mas do primeiro choque há apenas o registro feito pelos documentaristas. Neste caso, temos acesso apenas a uma versão bastante reduzida disponível no Youtube ${ }^{5}$. Cerca de três segundos depois

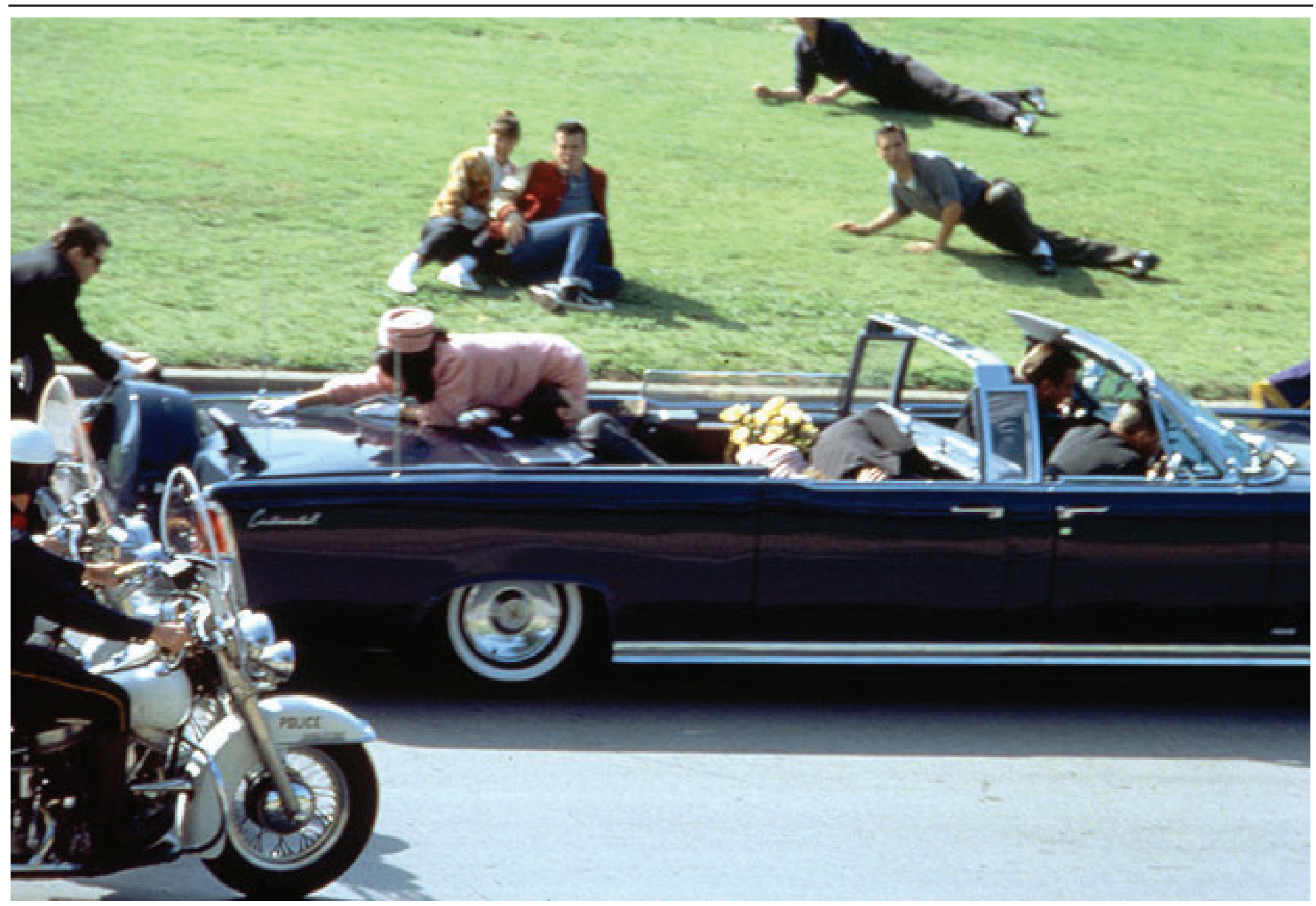

de iniciada a exibição do vídeo, um corpo estranho, um ruído sonoro e uma enorme sombra, fora de campo, no alto, interrompem a cena ordinária que enquadrava dois bombeiros parados numa esquina qualquer de Nova York. O cinegrafista mira o alvo móvel, aponta a câmera para o horizonte, onde estão as duas torres do WTC. Após quatro segundos, a aeronave choca-se contra a torre - mais correto talvez seja dizer que esta penetra o edifício, pois o que vemos é um buraco abrir-se, a sensa- ção visual é a de um objeto entrando na fachada e provocando uma explosão. O operador - um cameraman experiente - aciona de imediato o zoom e aproxima do ponto atingido pelo ataque. Registra fogo e fumaça brotando da torre. Ao fundo, gritos de surpresa e alarme.

A estrutura do vídeo em si difere do flagrante do assassinato de Kennedy na quase total ausência de espera. Mal o vídeo inicia e algo irrompe. E há uma certa demora, uma duração alongada no que poder-se-ia

53 PORTO ALEGRE | v. 19 | n. 32 | 2014 | pp. 52-60 Sessões do Imaginário 


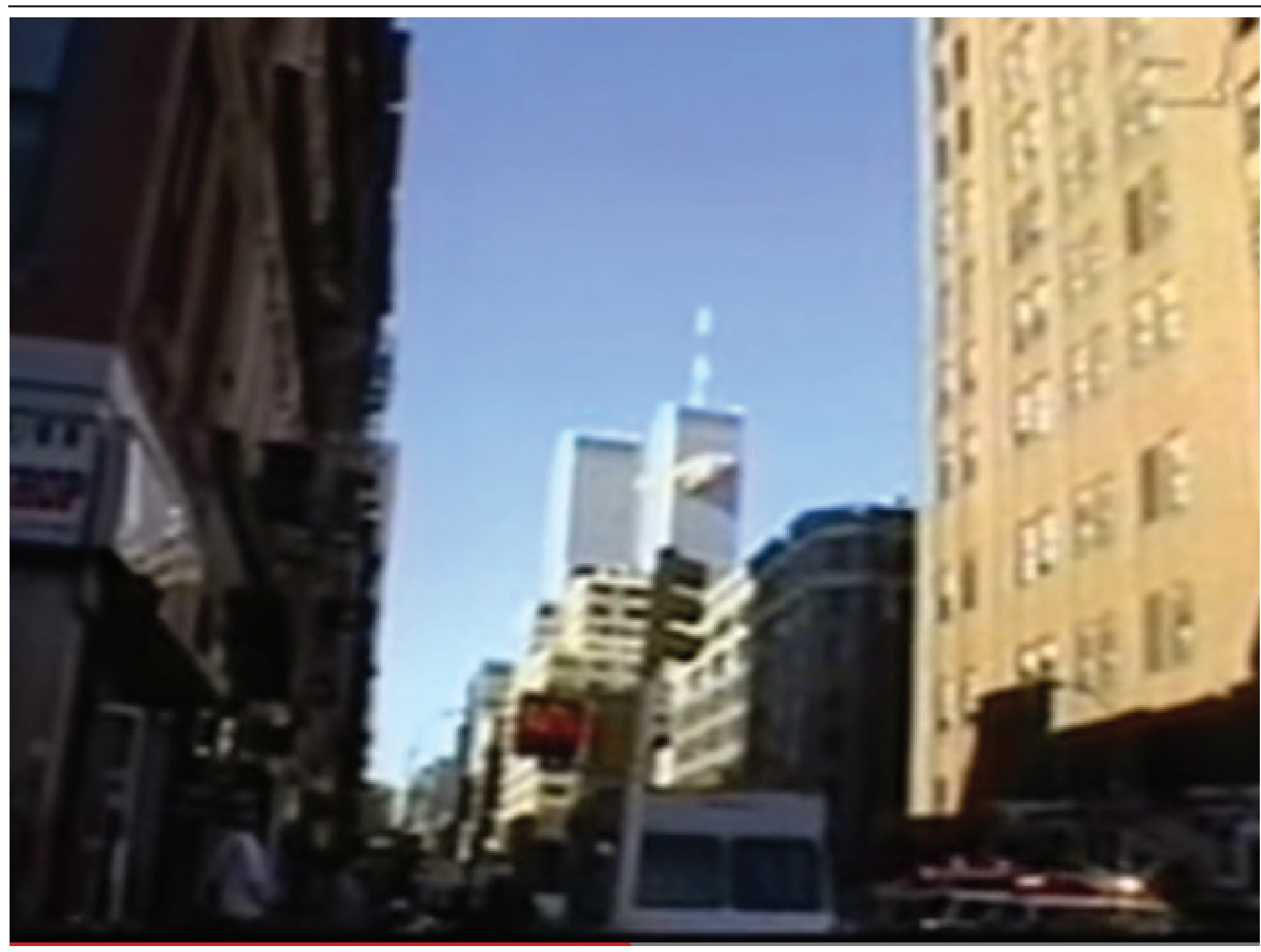

definir como o núcleo deste fato registrado nas imagens: desde o abalo no arranjo dos elementos internos graças à intrusão - inicialmente sonora, sutil, sugerida - de um algo ainda informe até a consumação desta espécie de roubo que o real protagoniza na cena: o choque do avião na torre do WTC, ato que dá a conformação final - num movimento retrospectivo - a este núcleo. Porém, igualmente em retrospecto, pode-se captar naqueles três segundos iniciais do vídeo, quando um grupo formado por dois bombeiros, um guarda e um outro sujeito conversam aguardando alguma coisa, a espera anterior, a longa estabilidade interrompida.

Em ambos os eventos, nota-se a estrutura típica de um acontecimento como entendido no jornalismo e nos meios de comunicação de massa:"tudo aquilo que irrompe a superfície lisa da história dentre uma multiplicidade de fatos virtuais" (Rodrigues apud Pontes e Silva, 2010, p. 51). O trajeto progressivo da mesmice ausência de substância relevante - em certo instante interrompida e desviada por um corte abrupto, que desestrutura o percurso anterior e institui um novo e ampliado processo de significação, cuja origem localiza-se neste instante inaugural e cujo centro produtivo se estende a todo núcleo deste fato primordial.

No acontecimento "assassinato de John Kennedy", estabelece-se o centro do evento com facilidade: o disparo homicida. Todas as ocorrências subsequentes aparecem como consequência desta causa original e as pretéritas são ressignificadas como preparo e anterioridade. A narrativa do acontecimento se deslinda rumo ao passado e o futuro estruturada em torno desta espécie de núcleo factual, o homicídio (disparo, atingimento), momento de descontinuidade e também causa de uma ampliação vertiginosa. O fundamental para nós é que este instante decisivo está registrado em imagem, no filme de Zapruder. Evidentemente, o filme não registra ou dá visibilidade à totalidade do fato "assassinato" - não apenas porque o atirador está fora de campo ou porque há todo um planejamento anterior de duração longa (dias? semanas? meses?), mas principalmente porque o fato, uma construção da linguagem, não é "totalizável". Didi-Huberman (2012) aponta o absurdo da ideia de que uma imagem - ou mesmo uma coleção delas - possa captar um acontecimento na íntegra. "Frequentemente pedimos muito ou muito pouco à imagem. Se lhe pedirmos muito - isto é, 'toda a verdade' - rapidamente ficamos decepcionados: as imagens não são senão fragmentos arrancados, pedaços peliculares" (Didi-Huberman, 2012, p. 52).

54 PORTO ALEGRE | v. 19 | n. 32 | 2014 | pp. 52-60 Sessões do Imaginário 
O filme de Zapruder, único documento audiovisual do instante da morte de Kennedy, capta o episódio da perspectiva de uma câmera. Reproduz o ponto de vista de um olhar, com toda a potência do plano-sequencia, "o máximo limite realista de toda técnica audiovisual" (Pasolini, 2006). No entanto, o espectador do filme - o internauta que o assiste hoje no Youtube, por exemplo - terá sua experiência visual limitada pelo enquadramento. Vê-se as ações e reações situadas dentro do quadro. Quanto ao que ocorre fora, pode-se intuir, deduzir, imaginar (a recepção da maioria dos espectadores, porém, estará determinada pelas narrativas - reportagens, recriações ficcionais - que já circularam sobre este evento massivamente comentado há cinquenta anos). É claro que chamar o filme de Zapruder de um registro pode levar a conclusões equivocadas (como se fosse a mera gravação de um fato bruto da realidade tal qual como ocorreu ao vivo, uma separação estanque entre o fato e sua documentação em filme). Um acontecimento midiático é o conjunto de seus documentos, registros, memórias, narrativas, relatos. A filmagem amadora de Zapruder não se resume a um documento que propicia o acesso a um fato histórico: está entre as peças documentais preponderantes na construção deste acontecimento. Há um assassinato violento no mundo empírico, por certo, mas toda a dimensão "evenemencial" erige-se em outro plano. A bem da verdade, é um equívoco pensar em termos de divisão entre fato e representação midiática, tendo em vista que o midiático enquanto paradigma cultural (enquanto modo de ser da realidade e modo de estar no mundo) encontra-se na origem de todos os fatos e decisões. Em um raciocínio simplório: ainda que se considere a morte de Kennedy não elucidada e ainda que datada do início dos anos 60, o pre- paro e planejamento do homicídio se dá em uma lógica midiática. Sendo assim, desde o advento de uma sociedade midiática ou do espetáculo, todo o acontecimento é inerentemente midiático, todas as estratégias e decisões carregam as formas desmaterializadas, imagéticas e agora virtualizadas do espetacular (e se a noção de acontecimento liga-se intimamente à de singularidade, o autêntico acontecimento, o verdadeiramente singular, talvez fosse aquele que quebrasse e/ou afrontasse as formas do espetáculo).

A estratégia espetacular evidencia-se com mais nitidez no ataque ao World Trade Center, evento pensado e executado - e isso, ao que parece, no nível mais consciente - para repercutir (para produzir horror, mas através da circulação intensa de imagens, relatos e narrativas).

Para a grande maioria do público, as explosões do WTC aconteceram na tela dos televisores, e a imagem exaustivamente repetida das pessoas correndo aterrorizadas em direção às câmeras seguidas pela nuvem de poeira da torre derrubada foi enquadrada de forma a lembrar as tomadas espetaculares dos filmes de catástrofe, um efeito especial que superou todos os outros. [...] Os próprios 'terroristas' não o fizeram primariamente visando provocar dano material real, mas pelo seu efeito espetacular. (Zizek, 2003, p. 25)

No episódio WTC, as três irrupções - o impacto do primeiro avião, do segundo e a queda das torres são objeto de filmagens (por emissoras de televisão, cinegrafistas amadores, etc.). Pode-se experenciar, via imagem, uma súbita e espetacular ocorrência (e, ao mesmo tempo, de violência extrema). O primeiro ví- deo talvez seja aquele no qual o efeito do abrupto é mais contundente: por ser o primeiro, aquele no qual se inscreve o fato inaugural, que provoca uma quebra. Percebemos essa quebra no próprio vídeo, mas também sabemos o quanto esse episódio representou uma ruptura. Um acontecimento no sentido forte.

A intrusão abrupta que é o núcleo desses vídeos reforça a ideia de que a estrutura do acontecimento envolve a irrupção de algo oriundo de outro lugar, outra ordem, outro espaço, outro tempo; evento que acaba por ressignificar tudo o que vem antes como espera e o que vem depois como consequência. ${ }^{6} \mathrm{~A}$ própria irrupção vira, assim, causa de fatos posteriores. Mas há outra causa que é a causa eficiente da intervenção do real na realidade, força exógena que arremessa o objeto da obscuridade, que é anterior, não está reproduzida enquanto objeto realista na cena, e sugere de si apenas um vislumbre (pisca, mas pisca tão rápido que não se transmuta em imagem).

Tomados de forma ampla, esses acontecimentos não decorrem do acaso - como dito, há estratégias e decisões anteriores a suas ocorrências, inclusive voltadas à produção de imagens violentas. No entanto, esses objetos audiovisuais que captam o instante de irrupção desses acontecimentos transmitem uma potência ou mesmo uma violência resultante do fato flagrado que parecem ultrapassar (ou localizar-se aquém ou além) da dimensão discursiva. Qual o estatuto dessas imagens, o que são em si e qual a relação frente ao fato filmado? Desde já, é fundamental esclarecer que a intrusão do real a que nos referimos não remete a um objeto acabado e estável, uma substância no sentido aristotélico, mas é da ordem do movimento e do devir; ostenta o status de evento e não de coisa estabilizada. Seguindo o pensamento de Heidegger 
(2008): um ser ou evento cuja qualidade de aparecer já desaparecendo é o que o define naquilo que ele é em si mesmo, de mais essencial e verdadeiro; cujo traço fundamental encontra-se na recusa a mostrar-se. O real como encontro faltoso, impossível de ser simbolizado, na definição de Lacan (1988).

Digamos que, de alguma maneira, este real encontra-se presente nessas imagens e que nem a circulação acelerada dos vídeos, nem as milhões de exibições em diversos sites, nem a captação numa linguagem essencialmente desprovida de referente (a digital), nem as inúmeras manipulações efetivas ou potenciais nos vídeos por meio de softwares de edição; nada disso esvazia ou desprovê estas imagens da violência que é da ordem do real. Mais: esta potência do real, este algo que olha de volta quem olha a imagem, responde, pelo menos em parte, pela audiência massiva e a circulação multiplicada de algumas dessas imagens. Dito de maneira simplória: é o que atrai o olho de tantos espectadores e, no contexto da cibercultura, os torna distribuidores fiéis de tais vídeos (o que não quer dizer que todo vídeo de forte circulação e impacto popular nas redes digitais traga inscrito este real). Diga-se ainda que a disseminação acelerada de câmeras, seja em equipamentos eletrônicos móveis, sejam aquelas voltadas à vigilância, eleva consideravelmente a quantidade de imagens que captam e, de alguma forma, reproduzem a supramencionada irrupção.

A tentativa de teorizar a respeito desta aparição de um real violento e traumático cujo traço mais essencial está em desviar da dimensão do visível oferece perigos. Tratando sobretudo das artes visuais, Rancière (2009), por exemplo, alerta para o uso excessivo e pouco preciso da expressão "irrepresentável" para designar os eventos e as coisas - ou as parcelas de eventos e coisas - que não podem ser representadas. Por isso, em busca de elementos teóricos sólidos para referenciar a reflexão acerca do estatuto dos vídeos que capturam o momento de intrusão do real (e sobre a presença de um suposto irrepresentável), prosseguiremos esta investigação tomando como base sobretudo a teoria de Jacques Lacan.

\section{Real versus realidade}

A multiplicação de registros visuais - sejam obra de amadores, profissionais, câmeras de segurança - tem propiciado um caminho de renovação das estéticas realistas. Trata-se de um fenômeno midiático contemporâneo que contém duas características marcantes do longo trajeto do estilo realista, como apontam, por exemplo, Auerbach (2011) e Brooks (2005): trazer uma porção cada vez maior da realidade para o domínio do visível (seja por meio de signos verbais, seja por imagens); e, além disso, retratar o cotidiano do cidadão comum. No campo do audiovisual, tal assertiva vale tanto para os registros cujos referentes factuais estão no mundo histórico quanto para as produções ficcionais e seus espaços diegéticos. Observa-se nos objetos midiáticos contemporâneos em geral uma vontade de transparência e um privilégio do visível que já eram o motor do realismo do século XIX, quando surge tal conceito para designar os modos de representação calcados na imitação da realidade - embora deva-se ressaltar, como informam Auerbach (2011) e Gombrich (2007), que o ímpeto mimético nas artes não surge ali, mas milênios antes, na Grécia Antiga, e que a mímese sempre esteve entre as estéticas prevalecentes em períodos dominados pelo pensamento lógico-racional.
O que há em anos recentes, sobretudo acompanhando o espraiamento das redes informáticas e dos equipamentos eletrônicos digitais, é uma intensificação na produção e circulação de imagens (de todas as estirpes), processo que abarca também os registros realistas. Vê-se, por exemplo, a incorporação de flagrantes e outros tipos de vídeos anônimos em telejornais e no cinema, além de uma estética ficcional que imita o amador, o caseiro e as câmeras de segurança com vistas a produzir efeitos de real - uma opção estética que realça a presença do dispositivo como maneira de simular um contato mais imediato com a realidade visível.

Para Baudrillard (1991), vige na cultura ocidental contemporânea uma promessa de duplicação integral da realidade, redundando em um esvaziamento do que havia de substancial e de autêntico e, como contrapartida, a nostalgia de uma relação mais imediata, concreta - no sentido físico, inclusive - com as coisas do mundo. De certa forma, é o diagnóstico que Zizek (2003) faz do domínio da "paixão pelo real" (conceito emprestado de Alan Badiou), revivificada neste início de século 21. Ocorre que o conceito de "real" em Zizek (2003), retirado da teoria de Jacques Lacan, difere daquele pressuposto no realismo na sua face racionalista. Tal distinção é fundamental para uma reflexão precisa acerca dos caminhos do realismo e de fenômenos culturais vinculados à multiplicação exponencial dos registros visuais. Na medida em que o real lacaniano define-se como o não-simbolizável, o resto impossível de captação pelos registros simbólico e imaginário, a própria premissa de dar visibilidade integral aos objetos do mundo - projeto essencial dos realismos - bate no muro da contradição. Nos três objetos audiovisuais citados anteriormente neste artigo, somente os eventos transparecidos na superfície do 
visível, isto é, os objetos, corpos e ações plasmados na tela, não dão conta da força dessas imagens. Há que se levar em conta o fundo e o fora de campo.

Os termos "real" e "realidade" vêm do latim res: coisa material, concreta. A etimologia já anuncia o sentido desses termos na modernidade. Designam algo que existe evidentemente porque pode ser tocado, apalpado, sentido, visto, reproduzido, representado, calculado e que se opõe à ilusão, à fantasia, aos produtos da imaginação. Definem a existência de algo que é em si mesmo, um objeto ou corpo, um conjunto de entes que existem de forma autônoma e independente, mas que podem ser conhecidos na íntegra. Gradativamente, esse conceito de real - sempre vinculado à noção de verdadeiro - se aproxima, com a evolução do método científico, da ideia de visível, conforme mostra Debray (1992). Não basta calcular, é preciso reproduzir a experiência, o que significa, cada vez mais, distinguir visualmente o objeto e o processo da descoberta científica (vide as novas gerações de equipamentos do campo da saúde que permitem enxergar, em si mesmos, os órgãos funcionando, elevando a exatidão das descobertas e a precisão de diagnósticos - e alcançando a proeza de, em linguagem simplória, fotografar o cérebro pensando).

$O$ real na sua acepção moderna, diz Heidegger (2008), é o objeto da ciência. E os procedimentos que visam a distingui-lo claramente ignoram aquilo que há de mais essencial nos entes. Existe algo de obscuro e esquivo no ser das coisas cuja interpelação intervencionista da ciência e da técnica moderna deixa escapar. Sendo assim, na modernidade, no domínio do mundo da técnica, a noção de real abrange somente a parcela dos existentes que responde à aproximação matemática e que, como tal, passa a ser dotada de uma existência concreta, efetiva. "No sentido de fato e factual, o 'real'se opõe ao que não consegue se consolidar numa posição de certeza e não passa de mera aparência ou se reduz a algo apenas mental" (Heidegger, 2008, p. 44). Do ponto de vista ontológico, portanto, o que o sujeito moderno chama de realidade - e que, para este sujeito, abrange toda existência concreta e efetiva - compõe-se apenas daquela parcela dos existentes seccionada de maneira a atender a visada racionalista e a precisão do cálculo. Uma noção em linha com a origem etimológica do termo. Mas este real que existe concretamente só é considerado real se puder ser observado, comprovado racionalmente e reproduzido, isto é, um objeto passível de cálculo e medição pelo sujeito cartesiano.

Já é dado como ponto pacífico o caráter cultural e histórico dos acontecimentos de ordem midiática. O discurso do jornalismo, por exemplo, não envolve a mera reprodução objetiva de fatos, a tentativa de representar e compreender o acontecido da maneira mais fiel possível, pressupondo um distanciamento anacrônico entre o referente bruto factual e o signo verbal ou imagético que o reproduz, tentativa de que o um da representação corresponda ao mesmo um do fato. O jornalismo sobretudo constrói o acontecimento. E o faz numa teia linguística crescentemente complexa, dada a profusão de signos, inclusive aqueles da alçada do receptor - que talvez já não possa mais receber essa denominação. Mas o que se busca investigar aqui, naquilo que chamamos de irrupção do real nas imagens (sobretudo nas imagens digitais que se multiplicam com os dispositivos móveis) é o resíduo que se encontra para além desta espécie de planificação que envolve a construção da realidade social, planificação que é uma das operações-chave do jornalismo. No nosso entendimento, a reflexão acerca de tal resíduo é necessária para dar conta das imagens citadas.
Tensão entre real e simbólico

Para Heidegger (2007), a época moderna ignora o que há de mais essencial nas coisas, dada a insistência em trazer os objetos para o domínio do visível, de alguma forma servir-se deles. No entanto, na abordagem das imagens que são objeto deste texto, evitamos falar em ser ou essência. Preferimos o termo real no sentido definido por Lacan (1988). O real lacaniano é algo com existência concreta, porém impermeável às ordens simbólica e imaginária cuja articulação engendra a realidade social. Em certo sentido, é o exato oposto do que o senso comum e a modernidade compreendem por "real". O real lacaniano não pode ser apreendido, nem visto, nem falado; muito menos medido e calculado. Mas nos assombra e, de certa forma, produz efeitos, pois, na primeira infância, ao entrarmos na ordem simbólica, perdemos para todo o sempre a capacidade de contatarmos tal dimensão. Trata-se de uma perda original cujo vazio consequente responde pela própria constituição do sujeito (compreendido numa chave estruturalista). Sendo assim, o real só pode ser definido no negativo: o impossível, na medida que não é possível atualizá-lo na rede significante.

Este núcleo duro inapreensível - ambíguo porque sua ausência da ordem simbólica gera a expectativa por preenchimento mas, ao mesmo tempo, é aquilo que dá sustentação ao simbólico e ao imaginário eventualmente irrompe e abala o equilíbrio do sujeito. A irrupção do real dá-se em um instante imprevisível, na forma de uma ruptura e um choque. E encontra-se fora da ordem simbólica do sujeito e da ordem imaginária do $\mathrm{eu}^{7}$; fora do consciente e do inconsciente; em resumo: emerge de um espaço ausente e acaba domesticado e dominado graças à intervenção da bateria significante, cuja vontade também não tem nada 
da noção de liberdade individual - na verdade, não há vontade, pois a articulação significante é contingente.

O fenômeno da irrupção do real pode ser pensado na dimensão individual mas também na coletiva. Zizek (1991), pensador de vertente lacaniana, cita o acidente da usina nuclear de Chernobyl como exemplo de intrusão do real na "realidade". Seriam alguns dos acontecimentos midiáticos exemplos de irrupção do real? Isto é: ainda que haja um processo de significação nitidamente construído a posteriori por signos de todas as espécies (textos, registros imagéticos e sonoros, etc.), esta construção ocorreria sobre e a partir de um cisma provocado pelo não-simbolizável? E, se por obra do acaso, temos o registro do instante mesmo da irrupção do real em vídeo ou em foto, qual o estatuto de tais imagens, onde e como o real se apresenta nesta imagem?

Uma chave para a resposta está na noção de "olhar", que Lacan (1988, p. 74) define assim:

Em nossa relação às coisas, tal como constituída pela via da visão e ordenada nas figuras da representação, algo escorrega, passa, se transmite, de piso para piso, para ser sempre nisso em certo grau elidido - é isso que se chama o olhar.

O olhar não é a visão, mas o chamariz nas coisas do mundo que atrai a atenção do olho. Em linguajar lacaniano, o olhar é o lugar do objeto pequeno $a$ na pulsão escópica. A constituição do sujeito dá-se a parti de uma perda original, o preenchimento de um vazio por parte do significante - que é, como dissemos, externo à consciência, da ordem da linguagem. Mas este preenchimento também é falho, pois uma característica do significante é jamais completar o sentido. Lidar com essas brechas passa a ser a condição do sujeito, cuja dialética constitutiva irá criar uma espécie de ilusão ou fantasia - o que o senso comum chama de realidade. Compensamos essa perda e cremos preencher as lacunas alienando o vazio original em objetos da realidade imediata. É aí que entra o que Lacan chama de objeto $a$, o objeto que por definição jamais poderá ser alcançado mas cujo efeito é causar o desejo, que por sua vez estará projetado em objetos efetivos da vida. O objeto a surge do efeito do simbólico sobre o real, processo de significação liderado pelo significante e que não se completará na íntegra, deixando um lapso que será encoberto pelas imagens da ordem do imaginário (daí depreende-se que a imagem é um vazio que esconde outro vazio). Tais imagens obviamente não saciarão o desejo, gerando no sujeito a pulsão. Isto é: o movimento sempre insaciado em direção ao objeto $a$, numa trajetória que tangenciará esta coisa inexistente, mantendo o desenrolar ininterrupto do desejo e da pulsão - no fundo, o objetivo último da pulsão é apenas gerar mais pulsão.

Na pulsão escópica, o movimento em questão é o do ver. Ver o quê? O olhar, o lugar ou posição de um objeto ou imagem no qual o objeto $a$ está alienado. $O$ ponto no campo escópico que nos olha de volta, isto é, que de alguma forma ocupa uma posição fundamental e se destaca, torna-se atrativo. O olhar (e o objeto $a$ ), embora fugazes, não são o real. Encontram-se no interstício entre o real, o simbólico e o imaginário. $\mathrm{Na}$ verdade, o esquema da pulsão escópica serve para organizar a visão. Porque o real mesmo não pode ser visto e sua proximidade gera angústia e não satisfação. Por isso, a intrusão do real, o instante de seu vislumbre, provoca o acionamento do aparato simbólico que produzirá novamente a estabilidade por meio de imagens com o estatuto de semblante. A tensão entre o vislum- bre de um núcleo bruto e a necessidade de cobri-lo talvez seja um dos aspectos centrais das imagens aqui em questão. Sendo assim, não se trataria apenas de representação ou inscrição do real não-simbolizável, mas, de alguma forma, de reprodução ou registro do jogo, tensão, conflito entre o real gerador de angústia e a estabilização pela via simbólica.

Vamos recorrer a mais um evento recente para finalizar esta reflexão: a captação na forma de vídeo do meteorito que caiu na Rússia, no dia 15 de fevereiro de 2013. No Youtube, há inúmeros testemunhos audiovisuais da ocorrência. Em geral, os vídeos repetem a estrutura. Alguns segundos de transcorrência banal, a súbita invasão de um objeto luminoso que atravessa o céu, com crescente brilho, até que o objeto desaparece. Em seguida, ouve-se uma explosão. Há também vídeos que não enquadram o céu, mas captam ou apenas a luminosidade ou apenas o som da explosão, além de eventuais danos materiais, como a quebra de vidros provocada pelo choque do meteorito. Mesmo nesses, nos quais não se enxerga o movimento do meteorito no céu, a estrutura é marcada por uma intervenção externa. Enfim, em todos os vídeos, algo irrompe e produz um corte que se assemelha à descrição lacaniana da intrusão do real.

Vejamos um vídeo específico ${ }^{8}$. A duração total é de apenas 32 segundos. Uma câmera dentro de um carro em movimento filma o horizonte. O automóvel se desloca em uma estrada ladeada por árvores, o céu ainda está um pouco escuro, levemente iluminado a partir de baixo; aparentemente, o sol está nascendo. Após nove segundos, logo depois de o carro virar à direita, no alto, à esquerda, surge um pequeno ponto luminoso. Este ponto inicia uma trajetória descendente numa orientação diagonal de cerca de 30 graus, em direção ao centro da imagem, deixando um rastro de fumaça 
semelhante ao dos aviões. O objeto luminoso aumenta gradativamente de tamanho, tendência agravada pelo fato de que o carro trafega em direção ao objeto. No instante 20", o brilho se intensifica e avoluma, raios luminosos são jogados para todos os lados, há um reflexo na estrada; vemos um clarão no centro da tela. Teria o objeto misterioso explodido? Impossível saber com base apenas neste vídeo. Não há som algum vindo de fora, somente o do rádio do carro. Mas é o que parece, pois, em seguida, o corpo diminui novamente e, mantendo a mesma trajetória, desaparece no horizonte. Portanto, o que se testemunha neste vídeo de 32 segundos é um objeto cadente misterioso irromper de maneira imprevista e, literalmente, cortar o céu.

Para o espectador que assiste ao registro da queda do meteorito no Youtube, o fato já chega preenchido de significados (neste site, os títulos dos vídeos costumam identificar explicitamente o que será visto). Na verdade, num evento dessa magnitude, com mais de mil feridos, logo depois da ocorrência mesma, os meios de comunicação partem para o que comumente se chama cobertura, ter mo muito apropriado, porque se trata mesmo de cobri um evento de significados. Primeiro, os jornalistas oferecem as informações mais básicas: o quê, onde, quando as consequências; números. Depois, os porquês. De um lado, entrevistas com cientistas, astrônomos; de outro, depoimentos de testemunhas, mais registros em vídeo e foto. Comentários e imagens compartilhadas à exaustão por usuários de redes sociais. Multiplicação indefinida de signos. Ou seja, a construção do acontecimento midiático envolve a operação rumo ao domínio da ordem simbólica e, junto, à cristalização e à estabilização do fato na ordem imaginária. Importante: tudo tendo como ponto de partida o evento inicial, epicentro jamais integralmente conhecido a partir do qual irradiam significados.
Contemporânea a este movimento de espiral simbólica é a repetição das imagens do evento inicial. $\mathrm{O}$ acontecimento se expande a partir deste núcleo original, mas o documento visual do momento da irrupção do meteorito sempre retorna. Vídeos editados que combinam diferentes registros da queda do meteorito estão entre os mais visualizados no Youtube. O fenômeno é visto e revisto por diferentes ângulos. Não se trata, aqui, de um claro conflito entre o testemunho do evento original - misterioso e inexato - e a cristalização do mesmo em imagem?

Falando pragmaticamente, em nenhum momento vê-se o meteorito. Nem a própria coisa, nem o evento do impacto. Nos diversos registros do objeto cortando o céu, o meteorito é um ponto luminoso que desaparece no horizonte após um clarão. Noutros vídeos, o ser do corpo espacial resume-se a um som de explosão e efeitos como estouro de vidros. Finalmente, como resultado direto da queda, o que temos é a imagem do buraco aberto pelo meteorito em um lago congelado no norte da Rússia9. Em resumo: um corte luminoso no céu, o som da explosão, um buraco no gelo. Do ataque ao World Trade Center, acontecimento pródigo em documentos visuais, também estamos privados de cenas fundamentais: quase não há imagens de dentro das torres após o choque dos aviões. O vídeo da explosão da primeira aeronave captado pelos documentaristas franceses fornece uma cena impressionante, mas não se tem o testemunho visual do horror maior: a invasão na perspectiva interna dos edifícios, o despedaçamento e a carbonização de coisas e corpos humanos. E mesmo que o ímpeto de transparência e a multiplicação de câmeras atingisse o feito - utópico, obviamente - de duplicar em imagem todo o espaço e todo o tempo, ainda assim, ficaria de fora a dimensão do real, cujo estatuto nas imagens é, essencialmente, o de uma falta.

\section{Referências}

AUERBACH, Erich. Mimesis. São Paulo: Perspectiva, 2011.

BAUDRILLARD, Jean. Simulacros e simulação. Lisboa: Relógio D'Água, 1991.

BERGSON, Henri. Duração e simultaneidade. São Paulo: Martins Fontes, 2006.

BROOKS, Peter. Realist vision. New Haven: Yale University Press, 2005.

D`ANGELO, Rinty; CARBAJAL, Eduardo; MARCHILLI, Alberto. Una introducción a Lacan. Buenos Aires: Lugar Editorial, 1984.

DEBRAY, Regis. Vie et mort de l'image. Paris: Gallimard, 1992.

DIDI-HUBERMAN, Georges. Imagens apesar de tudo. Lisboa: KKYM, 2012.

GOMBRICH, E.H. Arte e ilusão. São Paulo: Martins Fontes, 2007

HEIDEGGER, Martin. A Origem da Obra de Arte. Tradução: Laura de Borba Moosburger. In: "A Origem da Obra de Arte" de Martin Heidegger", pp. 05-80. Dissertação de mestrado. Curitiba: 2007. . “Ciência e pensamento do sentido". In:

Ensaios e Conferências. Petrópolis: Vozes, 2008. 
LACAN, Jacques. O Seminário 11: os quatro conceitos fundamentais da psicanálise. Rio de Janeiro: Jorge Zahar, 1988.

PASOLINI, Pier Paolo. "Observaciones sobre el plano-sequencia". In: Cinema: el cine como semiologia de la realidad. Cidade do México: Centro Universitario de Estudios Cinematograficos/UNAM, 2006.

PONTES, Felipe S.; SILVA, Gislene. "Acontecimento jornalístico e história". In: BENETTI, Marcia; FONSECA, Virgínia P. S. Jornalismo e acontecimento: mapeamentos críticos. Florianópolis: Insular, 2010.

RANCIÈRE, Jacques. The future of the image. London: Verso, 2009.

ZIZEK, Slavoj. Looking awry: an introduction to Jacques Lacan through popular culture. Cambridge: MIT Press, 1991.

Bem-vindo ao deserto do real! São

Paulo: Boitempo, 2003.

\section{Referências audiovisuais}

ZAPRUDER, Abraham. Zapruder Film of Kennedy

Assassination. [Filme-vídeo]. Direção de Abraham Zapruder. EUA, $1963.01 \mathrm{~min}$. color. son.
Notas

1 Uma versão deste trabalho foi apresentada no Grupo de Trabalho Cultura das Mídias do Encontro Anual da Compós, em junho de 2013.

2 A pesquisa que originou este artigo tem o apoio da Fundação de Amparo à Pesquisa do Estado de São Paulo (Fapesp).

3 Doutorando no Programa de Pós-Graduação em Meios e Processos Audiovisuais da Escola de Comunicações e Artes da Universidade de São Paulo (ECA/USP). Mestre em Comunicação Social e graduado em Jornalismo pela PUCRS. (ECA/USP - Av. Prof. Lúcio Martins Rodrigues, 443, Cidade Universitária, CEP: 05508-020, São Paulo/SP, Brasil). E-mail: felipepolydoro@gmail.com.

4 O vídeo está disponível neste link: <http://www. youtube.com/watch?v=1q91RZko5Gw.

5 O vídeo pode ser visto neste link: $<$ http://www.youtube.com/watch?v=IE82r4ycQs4>.

6 Numa visão ampliada, levando-se em conta os diversos acontecimentos midiáticos, pode-se dizer que tais eventos cumprem um papel amplo de marcar o tempo e, desta forma, organizar o trajeto progressivo da história no interior de um tempo que em si mesmo é absoluto, como aponta Bergson (2006). No entanto, por ora, não vamos discutir a dialética desses dois tempos dos acontecimentos: o do evento tomado individualmente e da soma dos acontecimentos que constroem a noção do tempo na contemporaneidade.

7 Conforme D’Angelo, Carbajal \& Marchill (1984), Lacan separa o indivíduo em duas partes: o sujeito do inconsciente (je, em francês) e o eu da ordem imaginária (moi, em francês). O sujeito é o produto da cadeia significante, a linguagem que se instala no inconsciente; o eu é o lugar da ilusão de totalidade do indivíduo, que imagina-se dono de suas ações e sua consciência.

80 vídeo está disponível neste link: <http://www. youtube.com/watch?v=V-0w3FPkXds $>$.

9 Neste endereço, há um vídeo que mostra o buraco no rio russo Chebarkul: <http://www.youtube.com/ watch?v=SZLPQtX2Pw4>. 